$15^{\text {th }}$ International Conference on

AEROSPACE SCIENCES \& AVIATION TECHNOLOGY,

$\boldsymbol{A S A T}$ - 15 - May 28 - 30, 2013, Email: asat@mtc.edu.eg,

Military Technical College, Kobry Elkobbah, Cairo, Egypt,

Tel: +(202) 24025292 -24036138, Fax: +(202) 22621908

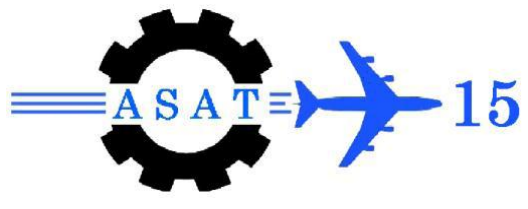

\title{
Computational Aerodynamics Analysis of a Light Aircraft
}

\author{
M. M. Abdulla*
}

\begin{abstract}
This work aims to study and simulate the flow field around light a/c using numerical solution based on solving Reynolds Averaged Navier-Stokes equations coupled with K- $\omega$ SST turbulence model.

Solution strategy began by analyzing wing alone then analyzing the whole a/c configuration. This strategy allows studying the wing flow field carefully and analyzing the vortices which occur over the wing and capture their effective regions at critical design conditions like stall condition. These regions were captured by plotting pressure contours and flow pathlines.

The aerodynamic behavior of this aircraft was investigated at different angles of attack and side slip angles. The $\mathrm{x}, \mathrm{y}$ and $\mathrm{z}$ forces and moments were calculated at flight speed of $50 \mathrm{~m} / \mathrm{s}$ and at sea level conditions. Lift and drag curves for different angles of attack were plotted. The maximum lift coefficient for this a/c was 1.67 which occurred at angle of attack $16^{\circ}$, the maximum lift to drag ratio (L/D) found to be 14 which occurred at $\alpha=3^{\circ}$, and the zero lift drag coefficient was 0.0342 . Also the yawing moment coefficient was plotted for different side slip angles as well as rolling moment.

The longitudinal stability derivatives with respect to angle of attack, speed variation (u), pitch rate (q) and time rate of change of angle of attack were calculated using obtained CFD results. Regarding lateral stability only side slip derivatives were calculated.
\end{abstract}

Keywords: Aerodynamics analysis, CFD, static stability.

\section{Nomenclature}

\begin{tabular}{llll}
$A$ & Aspect ratio & \multicolumn{2}{c}{ Greek symbols } \\
$C_{D}$ & Drag coefficient & $\alpha$ & Angle of attack (deg) \\
$C_{L}$ & Lift coefficient & $\beta$ & Side slip angle $(\mathrm{deg})$ \\
$e$ & Oswald span & $\tau$ & Shear stress $(\mathrm{Pa})$. \\
$u_{i}$ & Velocity & $\mu$ & Viscosity $(\mathrm{kg} / \mathrm{m} / \mathrm{s})$ \\
$C_{l}$ & Rolling moment coefficient. & $q$ & Pitching rate $(\mathrm{rad} / \mathrm{s})$ \\
$C_{m}$ & Pitching moment coefficient & $\varepsilon$ & Downwash $(\mathrm{deg})$ \\
$C_{n}$ & Yawing moment coefficient. & $\rho$ & Density $\left(\mathrm{kg} / \mathrm{m}^{3}\right)$ \\
$S$ & Wing area (m $\left.{ }^{2}\right)$ & & \\
$\operatorname{Re}$ & Reynolds's number & & \\
$x, y, z$ & Coordinate system & &
\end{tabular}

\footnotetext{
* Researcher, Aeronautical Research Center, Sudan, momahadi2007@ hotmail.com

Tel:+249915193162
} 


\section{Introduction}

Over the last 30 years, industrial airplane builders developed, manufactured, sold, and supported hundreds of billions of dollars' worth of commercial airplanes. During this period, it has been absolutely essential that the aerodynamicists have access to tools that accurately predict and confirm vehicle flight characteristics. Thirty years ago, these tools consisted almost entirely of analytic approximation methods, wind tunnel tests, and flight tests ${ }^{[1]}$. With the development of increasingly powerful computers, numerical simulations and various approximations of the Navier-Stokes equations began supplementing these tools. Petra Aumann et.al ${ }^{[2]}$ said that by the end of the 1980's, AIRBUS-D had put much validation effort into high level CFD technology. By the end of the 1990's, CFD itself was fully accepted and used within the aerodynamic design and data processes.

O.Brodersen and A.Sturmer ${ }^{[3]}$ from DLR Institute of design aerodynamics, Germany in the conference of AIAA Drag Prediction Workshop used Navier Stokes solver to predict the drag of a wing body combination. They compared their CFD results with other previous work in other commercial codes and validated their work by wind tunnel testing of the wing model.

In this paper, a general aviation aircraft, namely SAFAT 01, is to be analyzed from an aerodynamic approach to find the force and moment coefficients which are to be used to conduct open and closed loop control of the aircraft.

\section{Mathematical Model}

For analyzing the studied wing of SAFAT-01, the flow is assumed to be incompressible due to the maximum speed of $50(\mathrm{~m} / \mathrm{s})$. So, only Navier-Stokes equations with the K-Omega SST and continuity equation are solved simultaneously.

Mass conservation law:

$$
\frac{\partial\left(u_{i}\right)}{\partial x_{j}}=0
$$

Navier-Stokes Equations: These equations were employed in the following form ${ }^{[4]}$ :

$$
\frac{\partial \vec{q}}{\partial t}+\frac{\partial \vec{E}}{\partial x}+\frac{\partial \vec{F}}{\partial y}+\frac{\partial \vec{G}}{\partial z}=\frac{\partial \vec{R}}{\partial x}+\frac{\partial \vec{S}}{\partial y}+\frac{\partial \vec{T}}{\partial z}
$$

where

$$
\begin{aligned}
& \vec{q}=\left[\begin{array}{c}
\rho \\
\rho u \\
\rho v \\
\rho w
\end{array}\right], \vec{E}=\left[\begin{array}{c}
\rho u \\
\rho u^{2}+p \\
\rho u v \\
\rho u w
\end{array}\right], \vec{F}=\left[\begin{array}{c}
\rho v \\
\rho u v \\
\rho v^{2}+p \\
\rho v w
\end{array}\right], \vec{G}=\left[\begin{array}{c}
\rho w \\
\rho u w \\
\rho v w \\
\rho w^{2}+p
\end{array}\right], \\
& \vec{R}=\left[\begin{array}{c}
0 \\
\tau_{x x} \\
\tau_{x z} \\
\tau_{x z}
\end{array}\right], \vec{S}=\left[\begin{array}{c}
0 \\
\tau_{y x} \\
\tau_{y y} \\
\tau_{y z}
\end{array}\right], \vec{T}=\left[\begin{array}{c}
0 \\
\tau_{z x} \\
\tau_{z y} \\
\tau_{z z}
\end{array}\right]
\end{aligned}
$$

\section{Turbulence Model Equation}

Selection of turbulence model depends on the type of grid i.e. structured or unstructured grid. This model has a wide spread popularity among CFD researchers. For more information about this model see F. R. Menter et.al ${ }^{[4]}$. He states that this model is more accurate than kepsilon especially for near wall layers, and for flows with moderate adverse pressure gradients. 


\section{Geometry and Meshing}

The aircraft undertaken is SAFAT-01 which a light aircraft manufactured in Sudan intended to be converted to a UAV for mineral exploration and surveillance, the aircraft specifications summarized in Table1.

Table 1: Aircraft Specification

\begin{tabular}{l|c}
\hline \hline Wing area $\left(\mathrm{m}^{2}\right)$ & 15.87 \\
\hline Wing main aerodynamic chord length $(\mathrm{m})$ & 1.6 \\
\hline Gross weight $(\mathrm{kg})$ & 700 \\
\hline Maximum lift coefficient & 1.5 \\
\hline Minimum cruise speed $(\mathrm{km} / \mathrm{h})$ & 180 \\
\hline Airfoil & USA-35 B \\
\hline \hline
\end{tabular}

In this section, the CFD analysis scheme will be demonstrated. First the CATIA solid model is created to be suitable for CFD analysis. This required additional attention in creating the model by minimum faces and volumes, to prevent bad quality elements. The model is shown in Fig.1 below.

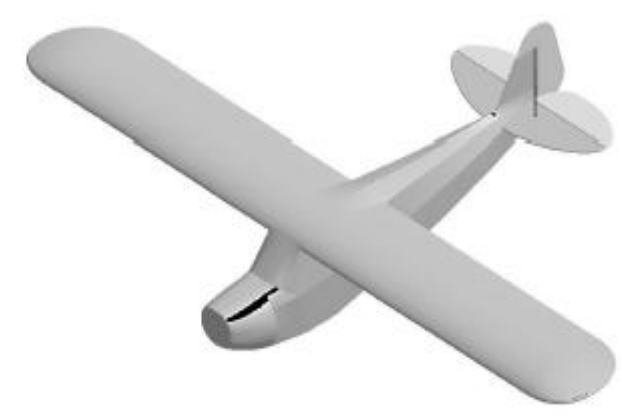

Fig. 1 SAFAT-01 3D model

\section{Grid Generation}

Computational domain is shown in Fig 2 with specified boundaries. The domain is created big enough to set far field values of velocity and pressure. Far field requires the lowest effect of wing downwash and wake behind wing and $\mathrm{a} / \mathrm{c}^{[5,7]}$. The radius of the sphere and cylinder length are $6^{*}$ span and $11^{*}$ span respectively.

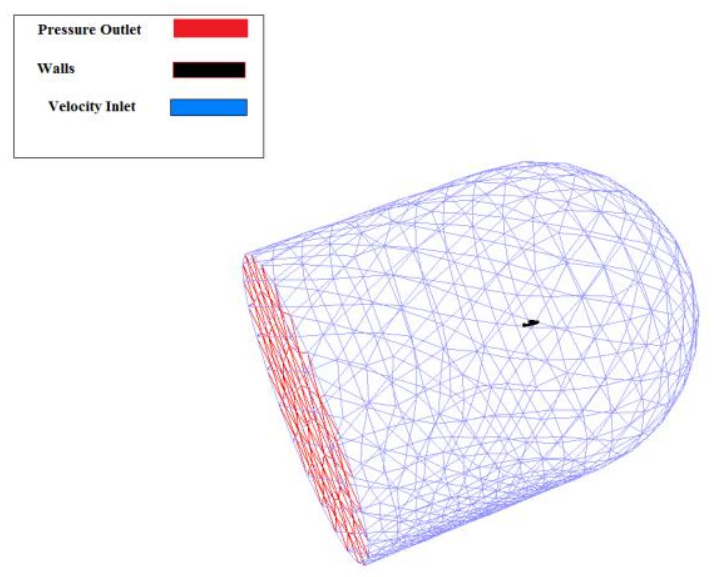

Fig.2 Computational domain and boundary conditions 
Figure 3 shows the mesh elements of SAFAT-01 full configuration (a) and wing (b). A fine mesh is focused near a/c surfaces to smooth surfaces as well as considering the boundary layer effect ${ }^{[6]}$. The interval size of the element is almost $2.5(\mathrm{~mm})$, which is created inside GAMBIT. The grid is of unstructured type with triangles and tetrahedral elements in the surface and volume meshes. Approximately 4 million cells were created in the computational domain of SAFAT-01.

For the wing also tetrahedral grid elements were constructed over the domain. 3 million cells were created.

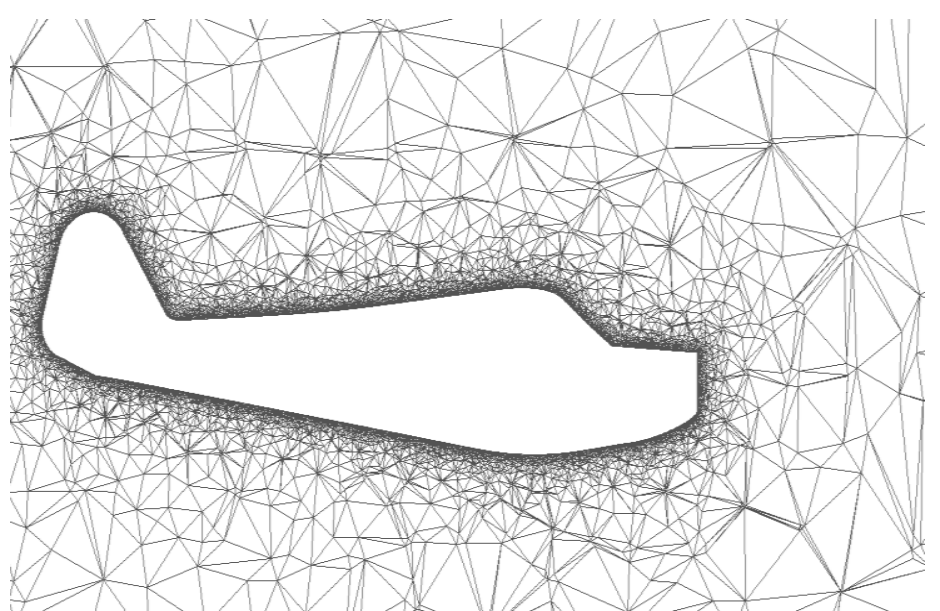

(a)

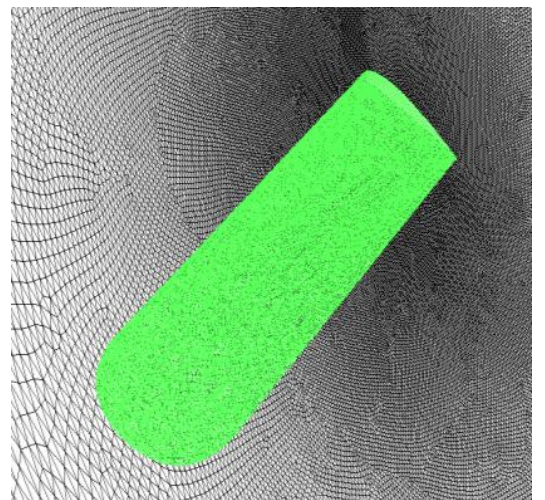

(b)

Fig.3 Grid elements for a) SAFAT-01 b) SAFAT-01's wing

\section{Results and Discussion}

Figure 4 shows the relation of lift coefficient plotted as a function of angle of attack at $\mathrm{Re}=5.4 \times 10^{6}$. This figure plotted for different configurations; whole a/c, wing, Horizontal Tail (HT) and body.

For aircraft body, it is observed that the lift is almost zero and has no any significant effect. Horizontal Tail curve shows that by increasing angle of attack the lift force increased, but the force is negative for $\alpha<8^{\circ}$, this causes a stabilizing moment about the a/c c.g.

From wing curve it is observed that, the wing stall angle of attack is $14^{\circ}, C_{L \max }=1.5$, where total a/c shows a value of $C_{L \max }$ about 1.67 at angle of attack $16^{\circ}$. Lift curve slope for a/c is equal to $0.0893\left(\mathrm{deg}^{-1}\right)$ where for wing equals to $0.0796\left(\mathrm{deg}^{-1}\right)$.

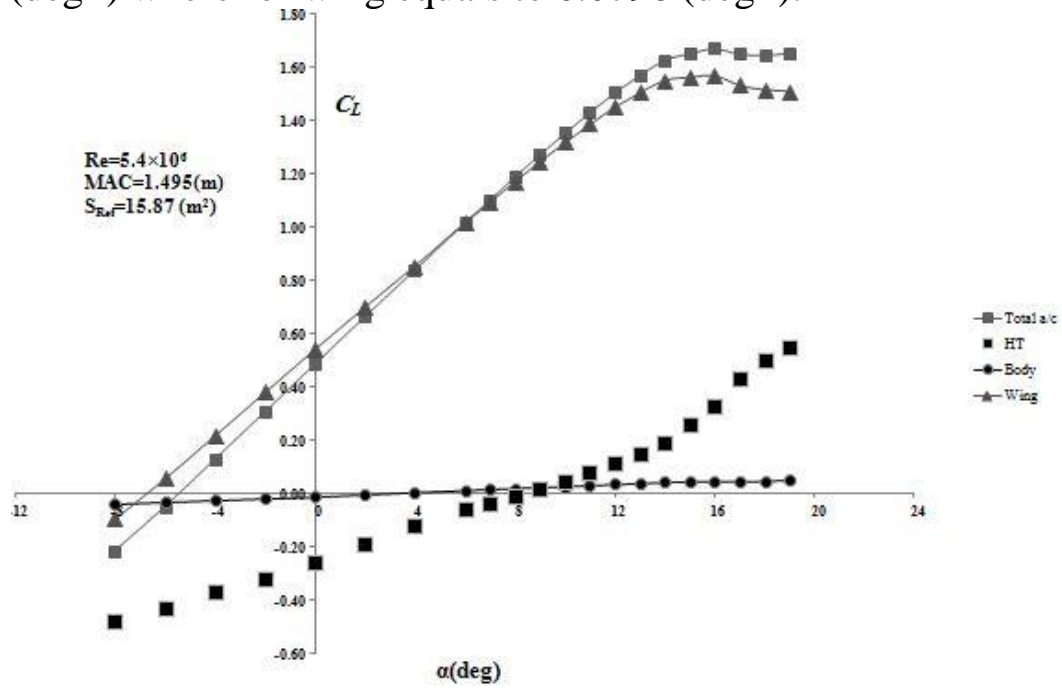

Fig.4 Lift coefficient vs. angle of attack (SAFAT-01 a/c) 
Figure 5 shows the widely known drag polar diagram, the relation between drag coefficient (y-axis) and lift coefficient (x-axis). The relation is a second degree nonlinear in the form of

$$
C_{D}=C_{D, 0}+K C_{L}^{2}
$$

The first term on the right side of the equation represents the parasite drag of the aircraft and the second represents the drag due to the production of lift force (induced drag). In order to simplify this equation, the induced drag may be written in the form of a coefficient of proportionality as in equation 3 .

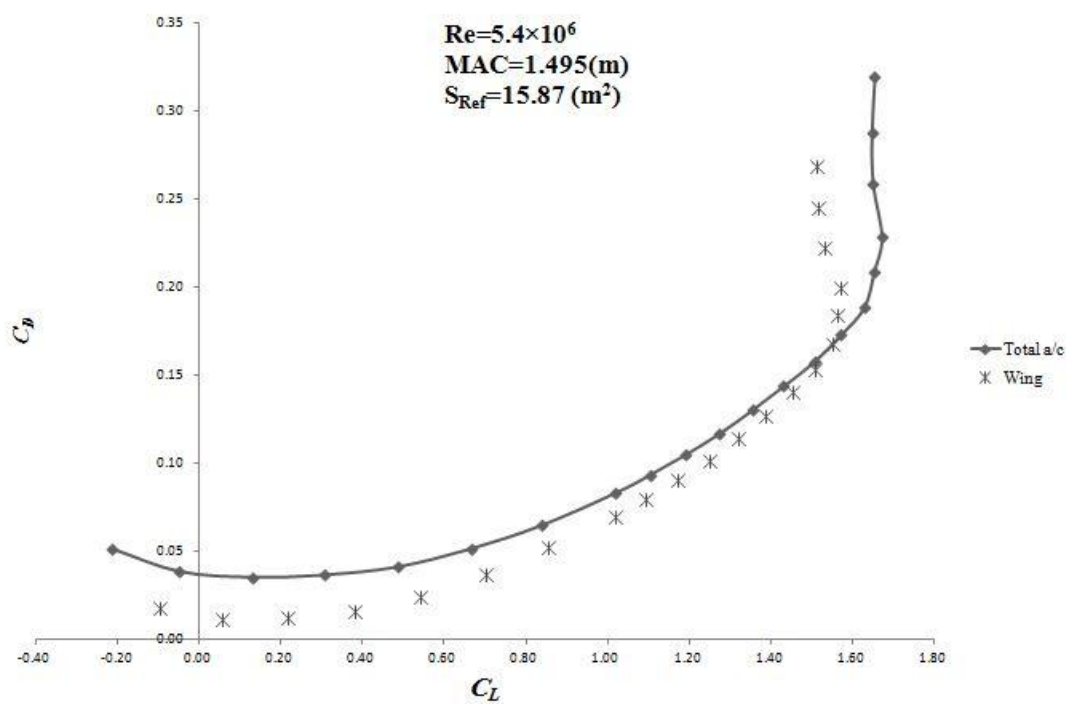

Fig.5 Drag polar diagram of SAFAT-01

Figure 6 shows the curves of pitching moment, $C_{M, c g}$ versus angle of attack, $\alpha$. The moment coefficient is measured at the center of gravity, which is located at 25\% MAC. In this curves the pitching moment coefficients for Horizontal Tail, Wing body, and total a/c were plotted, both HT and total a/c have the same trends; as the angle of attack increases, the moment decreases.

Wing-body configuration shows total instability; increasing angle of attack increases destabilizing moment which tends to stall the $\mathrm{a} / \mathrm{c}$ by increasing moment (negatively). Total $\mathrm{a} / \mathrm{c}$ shows that between the angle of attack $-8^{\circ}$ to $2^{\circ}$, the moment coefficients have a positive value. At this point, the a/c will tend to pitch upward. The stability criterion is satisfied for this a/c, that is the $C_{M, 0}>0$ and also $C_{M \alpha}<0$ as shown in Table 1.

The wing drag is producing a nose-down pitching moment. From fig. 6 , the a/c is is longitudinally stable. This is due to the higher location of wing drag line relative to the aircraft center of gravity; the a/c trim angle is $2 \mathrm{deg}$ which restricts a/c maneuvering capabilities.

Figure 7 shows the correlation between yawing moment coefficient and side slip angle $(\beta)$. The airplane is said to be directionally stable if it has an inherent capability to realign itself into the resultant wind whenever disturbed from steady level flight ${ }^{[6]}$. Mathematically, the requirement for directional stability criterion is that $C_{n \beta}>0$, and from this figure it is obviously that this criterion is satisfied.

Figure 8 shows the span wise lift distribution over SAFAT-01 wing in 10 different span stations. The wing-fuselage attachment has an effect of reducing the generated lift due to flow separation at this region. 


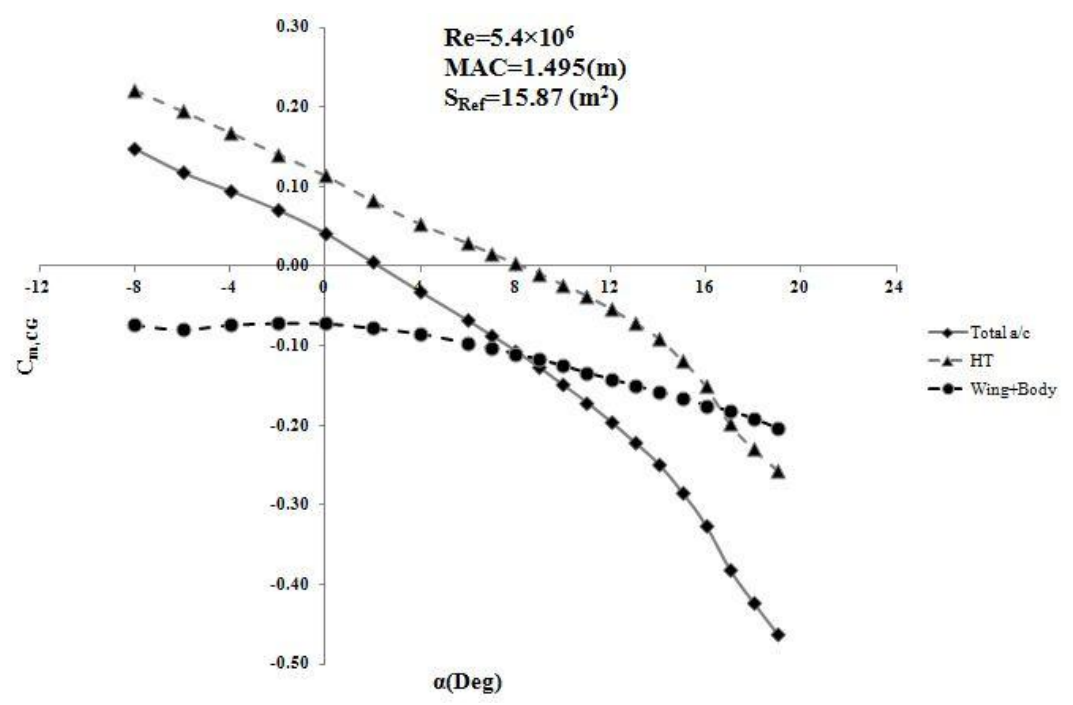

Fig.6 Pitching moment variation with angle of attack

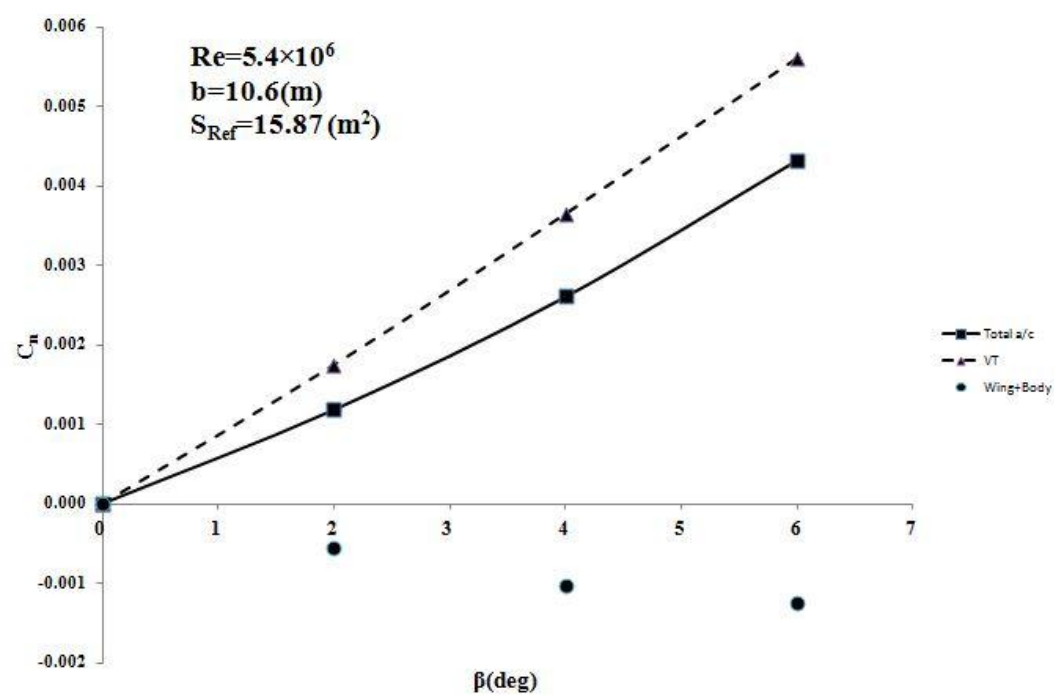

Fig.7 Yawing moment variation with side slip angle $(\beta)$

Figure 9 shows the flow pathlines over the upper surface of wing at $\alpha=16^{\circ}$. This figure indicates an existence of vortex on upper surface and tip vortices. The vortices zones are captured by the pencil and zoomed as shown in Fig. 9, this figure reveals that, the separation occurs near wing root first and starts to extend span wise by increasing angle of attack. Due to vortices near the wing root trailing edge it is predicted that wing flap may not be effective at $\alpha>16$.

Wing tip vortices also have high kinetic energy to swirl and rotate which increases the induced drag as a result; these tip vortices will then roll up and get around the local edges of the wing. This phenomenon will reduce the lift at the wingtip station, so they can be represented as a reduction in effective wing span 


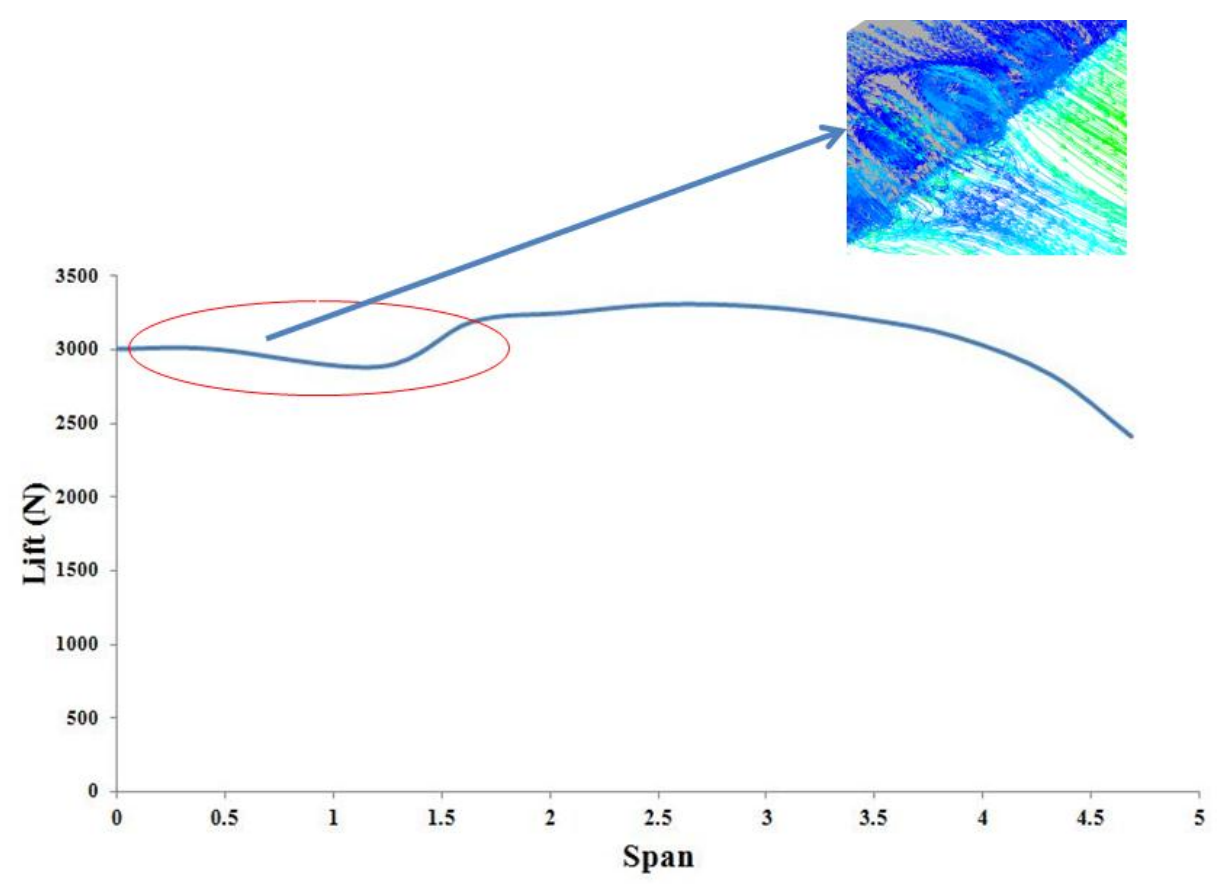

Fig.8 Spanwise lift distribution.

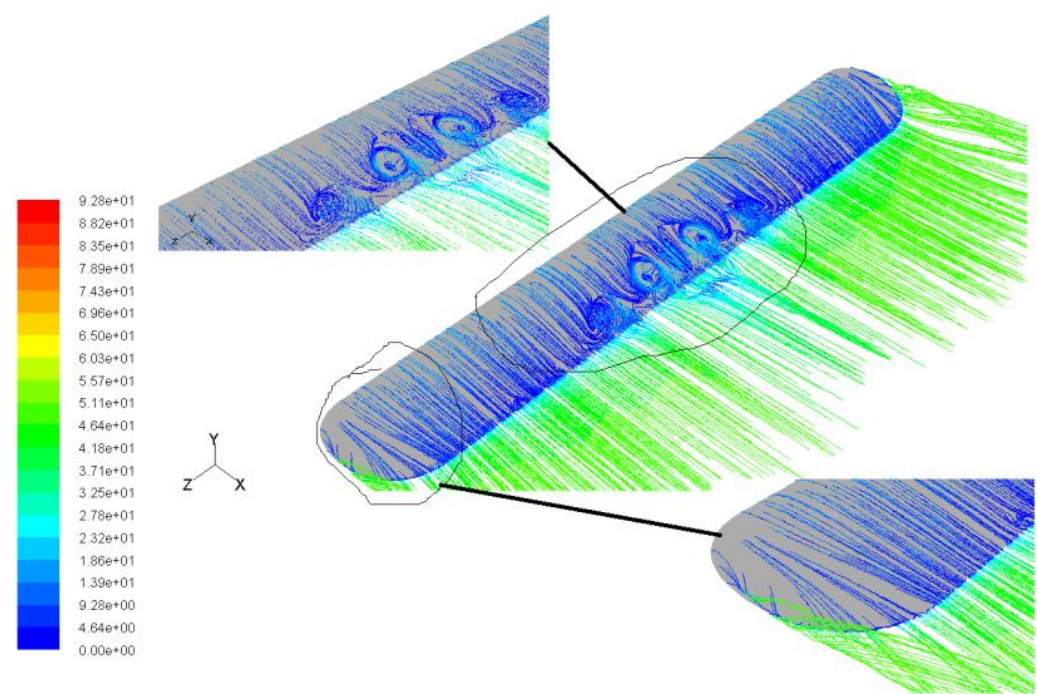

Fig.9 Flow pathlines over SAFAT-01's wing

Table 2 shows the estimation of stability derivatives using CFD results. The methods described in Ref [8] were used for estimating the coefficients. Due to incompressibility effect the terms $C_{x u}$ as well as $C_{m u}$ are zero.

Table.2: Stability derivatives

\begin{tabular}{|c|c|c|c|c|c|c|c|}
\hline$C_{L_{0}}$ & $C_{x \alpha}$ & $C_{z \alpha}$ & $C_{m \alpha}$ & $C_{m q}$ & $C_{Z q}$ & $C_{x u}$ & $C_{z u}$ \\
\hline 0.4870 & -0.0150 & 0.0900 & -0.0185 & -0.0740 & -0.0281 & 0.0 & -1.32 \\
\hline$C_{m_{0}}$ & $C_{m u}$ & $C_{n \beta}$ & $C_{y \beta}$ & $C_{l \beta}$ & $C_{z \dot{\alpha}}$ & $C_{m \dot{\alpha}}$ & $C_{D_{0}}$ \\
\hline 0.0420 & -0.003 & 0.00072 & 0.0077 & -0.005 & -0.8702 & -1.1123 & 0.03452 \\
\hline
\end{tabular}


The values of non-dimensional coefficients are obtained by assuming the body is rigid, and the coordinate system $\mathrm{x}-\mathrm{z}$ lies on the axis of symmetry, so $\mathrm{y}$ is span wise, $\mathrm{z}$ is vertical where $\mathrm{x}$ is longitudinal. This is explained when deriving the forces from FLUENT.

The derivatives related to time rate of change of the angle of attack were calculated using steady state CFD results with the formulae defined in [8]. The downwash was calculated using CFD to estimate $C_{z \dot{\alpha}}$ and $C_{m \dot{\alpha}}$

\section{Conclusion}

This paper studied the flow around SAFAT-01 a/c using numerical code namely FLUENT. The aircraft lift, drag, and pitching moment were calculated for angle of attack range from -8 to 20 degrees, also side force, yawing moment and rolling moment were calculated for side slip angle from 0 to 8 degrees.

The lift distribution is estimated along wing semi span at $\alpha=16$ degree at maximum level speed represents the maximum load factor obtained at pull up maneuver. The flow pathlines at $\alpha=16^{\circ}$ is captured and the stall pattern is shown,

\section{References}

[1] Edward N. Tinoco, "Thirty Years Of Development And Application Of CFD At Boeing Commercial Airplanes, Seattle", 16th AIAA Computational Fluid Dynamics Conference, 2003.

[2] Petra Aumann and Klaus Becker," MEGAFLOW for AIRBUS-D Applications and Requirements", AIAA, DLR, (2009).

[3] O. Brodersen, A. Sturmer, "Drag Prediction Of Engine-Airframe Interference Effects Using Unstructured Navier-Stokes Calculations", $19^{\text {th }}$ AIAA Applied Aerodynamics Conference, 2001.

[4] Florian R. Menter, "Improved Two-Equation k- $\omega$ Turbulence Models for Aerodynamic Flows", NASA Technical Memorandum 103975.

[5] H.K.Versteeg, W.Malalasekera, "An Introduction to Computational Fluid Dynamics The Finite Volume Method", Pearson Education Limited, 2007, Harlow, England.

[6] H.Schlichting, K.Gersten, "Boundary Layer Theory", McGraw Hill, 2000, N.Y.

[7] John Anderson, Jr. "Fundamentals of Aerodynamics", 5th edition, McGraw Hill, (2010), 981-1040.

[8] Bernard Etkin, "Dynamics of Flight Stability and Control", $3{ }^{\text {rd }}$ Ed, 1996, John Willey \& Sons, pp 129-156.

[9] Patankar, S. V. "Numerical Heat Transfer and Fluid Flow":Taylor \& Francis..

[10] AIAA $3^{\text {rd }}$ Drag Prediction Workshop Presentations by Marviplis and Tahran, http://aaac.larc.nasa.gov/tsab/cfdlarc/aiaa-dpw/Workshop3/workshop3.html, Retrieved at $1^{\text {st }}$ March 2011. 